OPTIMUM. STUDIA EKONOMICZNE NR 5 (89) 2017

\author{
Jerzy ZEMKE, Assistant Professor. \\ University of Gdansk \\ e-mail: jerzy.zemke@ug.edu.pl
}

DOI: $10.15290 /$ ose.2017.05.89.14

\title{
THE RISK OF HIPOTHECARY CREDIC INDEXED TO SWISS FRANC
}

\begin{abstract}
Summary
The idea of crediting and credit repayment is based on an assumption that each payment of the principal reduces the debt balance. This tendency is not followed in case of the hypothecary credit allowed and paid out in PLN and indexed to Swiss franc. Here, the balance of principal repaid in PLN is a function of currency exchange rate fluctuations. The situation denies then the idea of credit, according to which "you pay back as much as borrowed". The cost of credit, calculated as a total of the LIBOR - credit in CHF (WIBOR - credit in PLN) rate and the bank's margin specified in the contract. The purpose of the paper is to prove that a banking product like this does not meet the standards of crediting, the principal balance being dependent on the unforeseeable direction of changes.

The purpose of the paper is to design a model of risk of the hypothecary credit indexed to Swiss franc, to enable the measurement of the loan payment risk. The model design methodology assumes control variables of the risk monitoring process to be included in the model structure. The estimated loan payment risk measures have revealed an upturn in the loan payment risk related to higher PLN/CHF rates and the resultant higher cost of credit accompanied by the loan principal growth.

The risk dynamics estimations for the years 2006-2012 support the research thesis - the banking product analysed does not show the characteristics of a loan. Under growing PLN/CHF rates, the loan principal indexation translates into the debt balance escalation.
\end{abstract}

Key words: hypothecary credit, credit indexed to Swiss franc, credit risk of indexed to Swiss franc, risk measurement

JEL classification: G21

\section{Introduction}

The hypothecary credit market had been offering loans indexed to Swiss franc $\mathrm{CHF}$ - in Poland since the year 20001. They were granted and paid out in the domestic currency, but the lending bank recorded the credit in the currency of indexation, applying the rate of exchange as of the date of release. The product seemed advantageous to

1 Such products were also offered by banks in France, Peru, Turkey, Australia, Austria, UK, Montenegro, Island, Norway, Denmark, Spain, Hungary, Croatia. Indexation was applied to USD and EUR as well. 
borrowers, considering that high domestic currency base lending rates and the relatively low LIBOR translated into a low cost of credit.

The period between 2004 and 2014 saw the materialization of risk involved in the product which had been expected to solve the housing problem of many people in Poland $^{2}$. In the years 2004-2008, the PLN/CHF rate of exchange was showing a downward tendency. Over this period, the credit risk measured by the credit cost level was tending to decline.

The crisis faced by financial markets in mid-2008 changed this positive trend. With the growing PLN/CHF rate, the cost of loan servicing was increasing, while the new situation revealed a significant disadvantage of indexed credits, which was not known to borrowers at the time when the PLN/CHF had been falling, namely that the credit principal value was also indexed by the growing rate of exchange. As a result, the loan balance kept growing despite regular payments (Table 1).

TABLE 1.

CHF, PLN loan balance as per the CHF/PLN exchange rate; loan payable in PLN

\begin{tabular}{|l|c|c|c|c|c|}
\hline Due date & $\begin{array}{c}\text { Buy rate } \\
\text { [PLN/CHF] }\end{array}$ & $\begin{array}{c}\text { Sell rate } \\
\text { [PLN/CHF] }\end{array}$ & $\begin{array}{c}\text { Debt bal- } \\
\text { ance, varia- } \\
\text { ble instal- } \\
\text { ments } \\
\text { [CHF] }\end{array}$ & $\begin{array}{c}\text { Debt balance } \\
\text { converted } \\
\text { from [CHF] } \\
\text { to [PLN], } \\
\text { fixed instal- } \\
\text { ments (prin- } \\
\text { cipal + inter- } \\
\text { est) }\end{array}$ & $\begin{array}{c}\text { Debt bal- } \\
\text { ance, fixed } \\
\text { instalments } \\
\text { (principal + } \\
\text { interest) } \\
\text { [PLN] } \\
\text { /without in- } \\
\text { dexation/ }\end{array}$ \\
\hline 30.11 .2006 & 2.3817 & 2.4299 & 222671.00 & 541068.26 & 527389.53 \\
31.01 .2007 & 2.4039 & 2.4525 & 221907.56 & 544228.29 & 526203.88 \\
30.04 .2007 & 2.2759 & 2.3219 & 220778.06 & 512624.58 & 524382.44 \\
31.07 .2007 & 2.2864 & 2.3326 & 219664.41 & 512389.20 & 522508.14 \\
30.09 .2007 & 2.2475 & 2.2929 & 218938.10 & 502003.17 & 521228.48 \\
30.11 .2008 & 2.4149 & 2.4609 & 212958.60 & 524069.82 & 511553.56 \\
31.12 .2008 & 2.7365 & 2.7962 & 212487.68 & 594158.05 & 510811.80 \\
31.01 .2009 & 2.9547 & 2.9617 & 211943.95 & 627714.40 & 510062.93 \\
28.02 .2009 & 3.1422 & 3.1843 & 211373.09 & 673075.33 & 509306.88 \\
30.04 .2009 & 2.8994 & 3.0175 & 210217.48 & 634331.25 & 507772.98 \\
31.10 .2009 & 2.7790 & 2.8372 & 206664.54 & 586348.63 & 502991.76 \\
31.07 .2010 & 2.9276 & 2.9620 & 201097.76 & 595651.57 & 495286.78 \\
31.01 .2012 & 3.4988 & 3.5694 & 189197.23 & 675320.59 & 477743.11 \\
\hline
\end{tabular}

Source: Author's analyses.

2 About 700 thousand such loans were allowed in Poland, their total amount close to PLN 160 billion. 
The analysis of changes in the debt balance occurring over the years $2004-2008$ and until mid-2008 permits the definition of the product in question: the hypothecary credit indexed to a foreign currency - Swiss franc. This is a banking product, which does not have the main feature of a loan, since PLN/CHF rate fluctuations are reflected in the debt balance here, the monotonicity of variable depending on the direction in the currency exchange rate changes - see graphs: Fig.1.

FIGURE 1.

Loan balance changes: a loan in CHF, converted from [CHF] to [PLN] and a loan in [PLN] over the period 30.11.2006 - 31.01.2012.

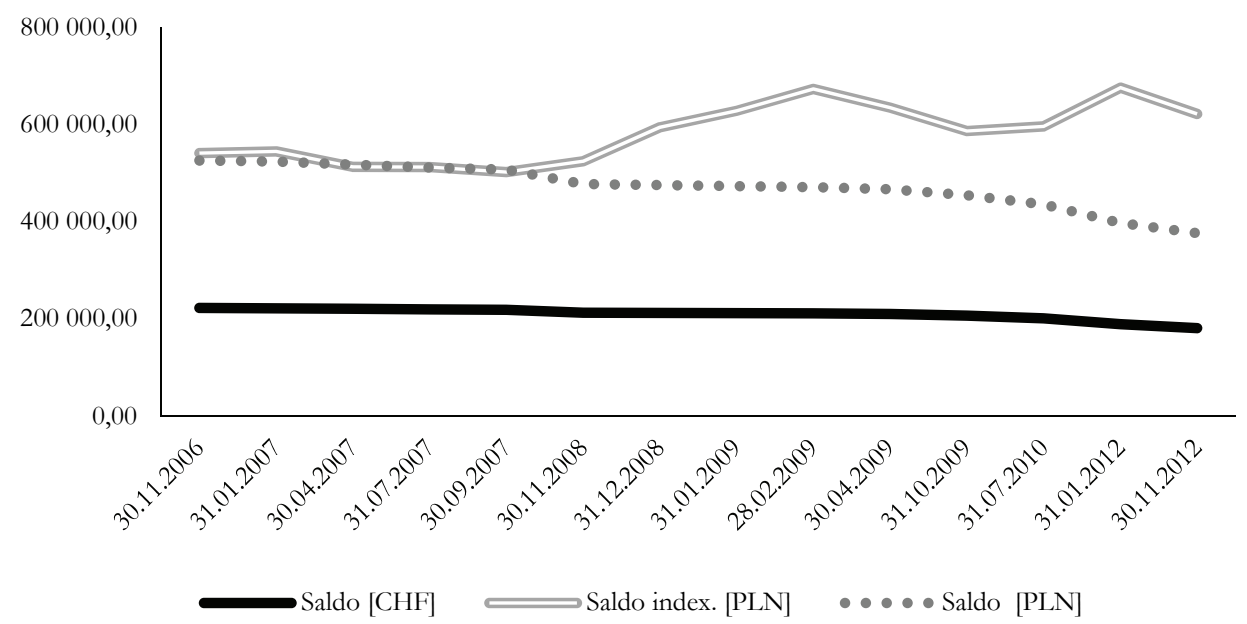

Source: Author's own analyses based on data from Table 1.

The loan balance is a function which is assumed to decrease over time. This property is independent on the scheme adopted for the payment of principal instalments. In the fixed principal instalment model, the debt balance decreases by the amount of the payment made. A similar tendency is observed in the annuity model, where payments are fixed, while the payment structure changes: the principal share grows, while the interest share decreases.

Thesis: the balance of the hypothecary credit indexed to CHF and structured according to the annuity payment model, is a monotonically growing random variable, if the indexation currency rate grows.

The uncertainty of tendencies in the PLN/CHF changes exposes borrowers to the risk of losing their financial liquidity as a result of a significant growth of the exchange rate. To provide protection against the exchange rate variations, it is necessary to measure the uncertainty status. The design of instruments to be used for measuring the occurrence of such unfavourable scenarios within the term of the credit defines the purpose of the study. 
Purpose of the study: design a risk model, define statistical measures of the borrower's risk over the term of the credit.

The structure adopted for the paper, consisting of the methodology, the results, the discussion and the conclusion allows to believe that the objective will be achieved and the research hypothesis - verified.

The choice of the reference literature has been determined by the methodology of the study. The approach chosen out the existing risk measurement models perceives risk as an effect of changes in the decision making environment. Hence, the research process was supported by the publications of the Author, where the risk model is a random vector and its components are symptomatic variables of the consequences of risk.

\section{Methodology}

Exchange rates fluctuations are determined by the situation on the financial markets, but also, as experience shows, are caused by currency speculations. Therefore, there is no doubt as to the qualification of the rate variability type: it is a scalable random variable, which means that the limits of the variability interval can be estimated.

Borrowers' choice to take the risk, despite being aware of the currency rates unpredictability, is merely a demonstration of their trust that if the exchange rate grows, the scale of growth will not exceed the level they regard as acceptable. The acceptable level of exchange rates is an essential element of the definition of risk involved in the payment of a loan under the currency rate growth.

Definition. The risk of the indexed credit debt growth is a state which accompanies the debt payment indexed to the rate of currencies other than the credit currency, caused by the currency rate growth above the acceptable level.

The risk of the credit debt growth is caused by the growth of the domestic currency to Swiss franc exchange rate. Hence, how should one measure the risk of changes in the credit debt level?

The indexation currency exchange rate fluctuations are the control variable of risk, therefore the risk model is a random vector with a single component: the exchange rate.

The risk model enables the identification of risk measures - it is a random variable, hence these are the random vector statistic measures:

1. The probability of an event that the credit currency - PLN - rate of exchange to the indexation currency - CHF - takes a value from a certain interval [a, b], assuming that the probability density function of the risk vector is $f(x)$, equals: $P(a \leq x \leq b)=\int f(x) d x$ - a definite integral defined on an interval $[\mathrm{a}, \mathrm{b}]$.

2. The random variable - rate of exchange - expected value: $E(X)=\int x f(x) d x[-\infty,+\infty]$. 
3. The random variable - rate of exchange - variance: $\operatorname{Var}(X)=\int(x-f(x))^{2} f(x) d x-$ an integral defined on interval $[-\infty,+\infty]$.

\section{Results}

The idea of measuring risk, as well as its practical utility in risk analysis were verified on data of a real-life hypothecary credit contract indexed to CHF. The loan amounting to PLN 527 thousand, the loan payment period of 21 year, the interest rate: LIBOR CHF plus a $4.4 \%$ margin, fixed payments (principal + interest).

Assumptions for the analysis:

1. The analysis covered a period from November 2006 to January 2012.

2. The CHF sell rate as of the date of the loan contract - PLN/CHF 2.4636 was used as the reference point for measuring the currency rate variations.

3. Risk was estimated based on an assumption that the acceptable risk level is associated with a $15 \%$ exchange rate growth against the contract date rate, i.e. 2.8330 PLN/CHF. The acceptable risk level falls into the PLN/CHF rate interval $[2,4636 ; 2,8330]$.

4. Risk was estimated based on currency rate quotations exceeding the acceptable level. Any quotations below this level were considered to represent an acceptable risk of the loan obligation payment.

5. Assumptions for the measurement of risk:

The distribution of the variable $\mathrm{X}$ probability distribution density follows normal distribution:

$$
f(x)=\frac{1}{\sigma \sqrt{2 \pi}} e^{\frac{(x \mu)^{2}}{2 \sigma^{2}}} \text {, with distribution parameters } \mu \text { and } \sigma \text {, this assump- }
$$

tion enables statistic measures of risk to be defined:

a. The probability that random variable $\mathrm{X}$ takes value from interval $[\mathrm{a}, \mathrm{b}]$ :

$$
P(a \leq x \leq b)=\frac{1}{\sigma \sqrt{2 \pi}} \int_{a}^{b} e^{\frac{(x-\mu)^{2}}{2 \sigma^{2}}} d x .
$$

b. The expected value of random variable $X$ :

$$
E(X)=\frac{1}{\sigma \sqrt{2 \pi}} \int_{-\infty}^{+\infty} x e^{\frac{(x-\mu)^{2}}{2 \sigma^{2}}} d x
$$

c. The variance of random variable $X$ :

$$
\operatorname{Var}(X)=\frac{1}{\sigma \sqrt{2 \pi}} \int_{-\infty}^{+\infty}(x-\mu)^{2} e^{\frac{(x-\mu)^{2}}{2 \sigma^{2}}} d x .
$$


Based on the risk measurement assumptions defined in point 3 and 4, measures $\langle P(X), E(X), \sqrt{\operatorname{Var}(X)}\rangle=\langle 0.5078 ; 2.4871 ; 0.0387\rangle$ were estimated. They were taken as an acceptable level of the exchange rate risk. Risk measures of the analysed period were estimated based on the Swiss franc - CHF - selling rate and point 5 of the risk measurement assumptions.

TABLE 2.

Statistical measures of currency risk [PLN/CHF]

\begin{tabular}{|c|c|c|c|c|c|c|}
\hline It. & $\begin{array}{c}\text { Sell rate } \\
{[\mathbf{P L N} / \mathbf{C H F}]}\end{array}$ & $P(a \leq x \leq b)$ & $\boldsymbol{E}(\boldsymbol{X})$ & $\begin{array}{c}\text { Var } \\
(\boldsymbol{X})\end{array}$ & $\begin{array}{c}\text { Standard } \\
\text { deviation }\end{array}$ & Due date \\
\hline 1 & 2.4299 & 0.5085 & 2.4468 & 0.0006 & 0.0238 & 30.11 .2006 \\
2 & 2.4525 & 0.2183 & 2.4487 & 0.0003 & 0.0172 & 31.01 .2007 \\
3 & 2.3219 & 0.6928 & 2.4170 & 0.0042 & 0.0649 & 30.04 .2007 \\
4 & 2.3326 & 0.6656 & 2.4001 & 0.0046 & 0.0677 & 31.07 .2007 \\
5 & 2.2929 & 0.7453 & 2.3822 & 0.0056 & 0.0747 & 30.09 .2007 \\
6 & 2.4609 & 0.0095 & 2.3935 & 0.0055 & 0.0744 & 30.11 .2008 \\
7 & 2.7962 & 0.4373 & 2.4438 & 0.0250 & 0.1582 & 31.12 .2008 \\
8 & 2.9617 & 0.5446 & 2.5014 & 0.0517 & 0.2274 & 31.01 .2009 \\
9 & 3.1843 & 0.6146 & 2.5697 & 0.0926 & 0.3043 & 28.02 .2009 \\
10 & 3.0175 & 0.5767 & 2.6104 & 0.1016 & 0.3187 & 30.04 .2009 \\
11 & 2.8372 & 0.4513 & 2.6293 & 0.0966 & 0.3108 & 31.10 .2009 \\
12 & 2.9620 & 0.5682 & 2.6549 & 0.0971 & 0.3116 & 31.07 .2010 \\
13 & 3.5694 & 0.7326 & 2.7202 & 0.1494 & 0.3865 & 31.01 .2012 \\
\hline
\end{tabular}

Source: Author's analyses based on PLN/CHF exchange rate data published on the Narodowy Bank Polski (Polish National Bank) website.

The currency risk measures estimated for the period from November 2006 to January 2012 [Table 2] have a significant informative value as regards the role of exchange rate risk in the financial liquidity management in respect of credit payment.

The probability of the currency rate growth showed a growing tendency in the analysed period. The exchange rate risk measure deviated unfavourably from the acceptable probability level. This level was defined in points 3 and 4 of the assumptions accepted for the risk measurement procedure in this study. 
FIGURE 2.

The probability of events that the PLN/CHF exchange rate will take values from the interval determined by the PLN/CHF selling rate as of the day of the credit release against the PLN/CHF rate as of the loan instalment payment

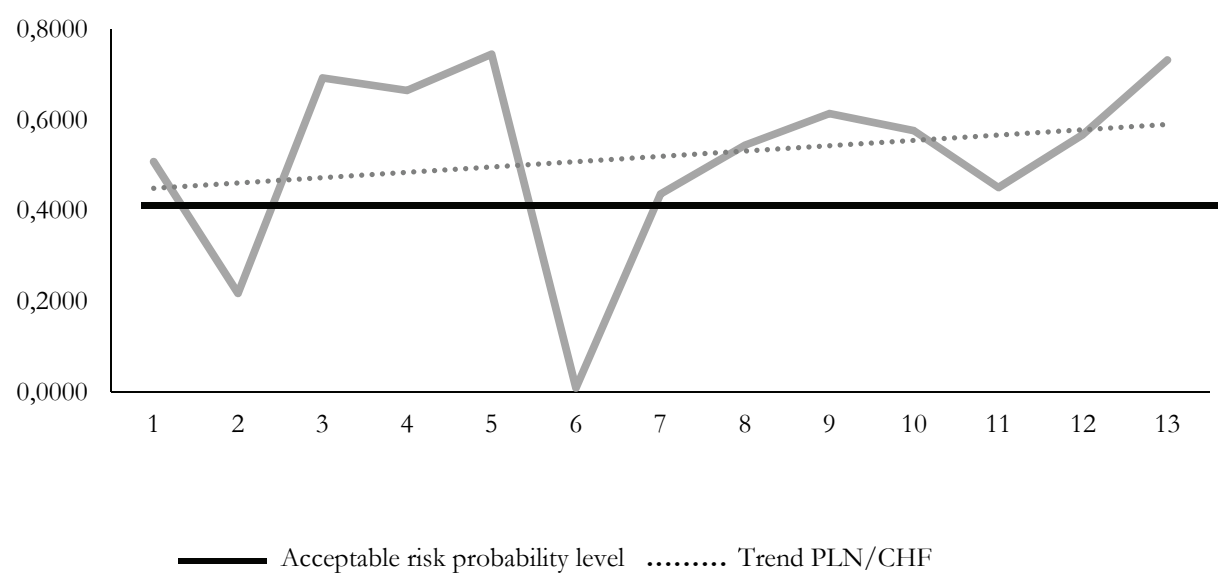

Source: Author's own analyses based on data from Table 2.

The PLN to CHF rate "entered the path of growth" in QIV 2008 and this tendency has been observed for more than five years now. Over this period, the probability of events resulting in the currency rate to "take" a position above the acceptable level (Fig. 2) increased significantly.

FIGURE 3.

Changes in the currency rate expected value

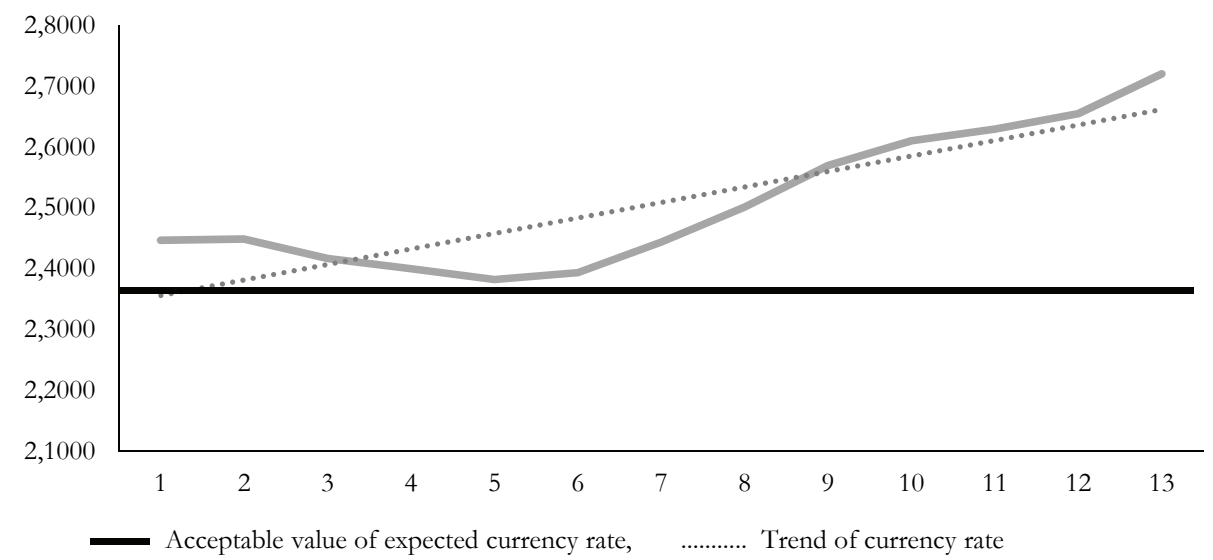

Source: Author's own analyses based on data from Table 2. 
The standard deviation [Fig. 4], representing the measure of the PLN to CHF rate deviations from the estimated mean values of the rate is showing exactly the same tendency. As far as the exchange rate expected value and deviation, the exchange rate risk measures are characterized by the same moment of the estimated measures "transition" over the level defined as acceptable.

\section{Changes in the currency rate standard deviation}

\section{FIGURE 4.}
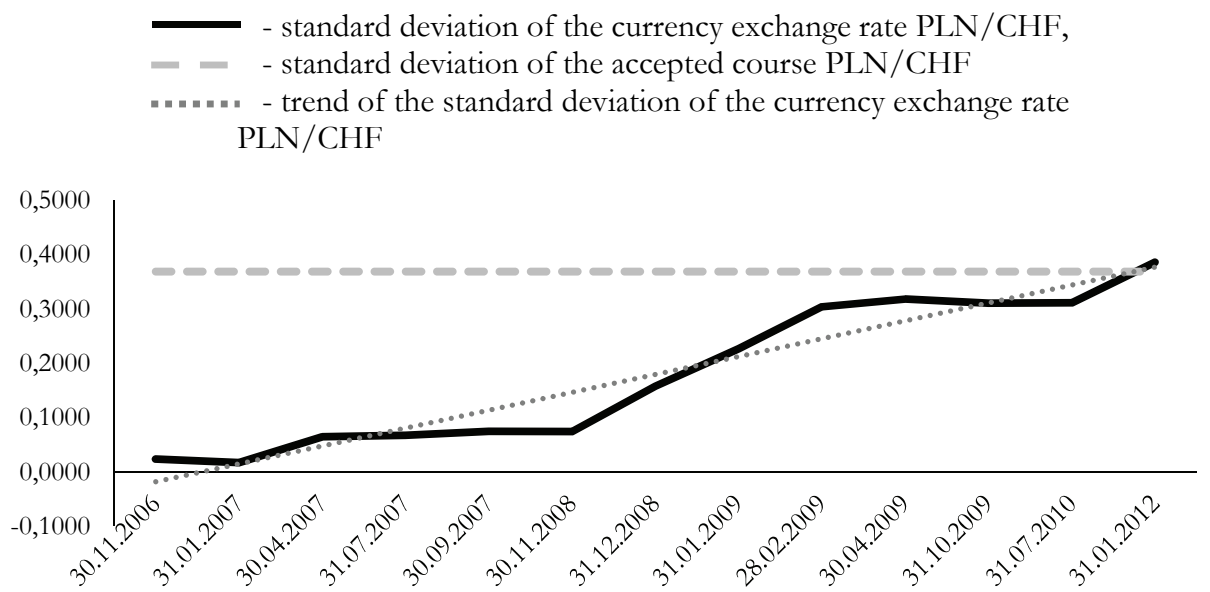

Source: Author's own analyses based on data from Table 2.

\section{Discussion}

A hypothecary credit indexed to $\mathrm{CHF}$ might be an excellent banking product, but it is subject to certain essential determinants. It would be competitive against loans in domestic currencies, but only provided a stable exchange rate throughout the payment term and a high national base lending rate. Meeting these conditions has been, is and most probably will be impossible. What threats will the indexation involve, considering the risk of the currency growth? This aspect has been referred to in the research thesis of the study and it is the right moment now to prove it.

Let $K_{0}$ stand for the loan principal, $\mathrm{R}$ - for the fixed payment under the annuity scheme, where payments, by definition, consist of a principal component and the interest on the loan principal balance to be paid: $R=k_{n}+p_{n}\left(K_{0}-\sum_{i=1}^{n-1} k_{i}\right)$, where $p_{n}$ is the loan interest rate in the $\mathrm{n}$-th period of the loan payment, $p_{n}$ is the currency rate 
function, and $k_{i}, i=1,2, \ldots, n$ is the principal payment. Let us designate respective principal payments in periods $(\mathrm{n}, \mathrm{n}-1)$ as:

$$
\begin{gathered}
k_{n-1}=R-p_{n-1}\left(K_{0}-\sum_{i=1}^{n-2} k_{i}\right), \\
k_{n}=R-p_{n}\left(K_{0}-\sum_{i=1}^{n-1} k_{i}\right), p_{n}=p_{n-1}+\Delta p \wedge \Delta p>0,
\end{gathered}
$$

The principal balance at moment $\mathrm{n}$ equals: $S K_{n}=S K_{n-1}-K_{n}$,

$$
\begin{gathered}
S K_{n}=S K_{n-1}-\left(R-\left(p_{n-1}+\Delta p\right)\left(K_{0}-\sum_{i=1}^{n-1} k_{i}\right)\right), \\
S K_{n}=S K_{n-1}-\left(R-p_{n-1}\left(K_{0}-\sum_{i=1}^{n-2} K_{i}\right)\right)+p_{n-1} k_{n-1}+\Delta p\left(K_{0}-\sum_{i=1}^{n-1} k_{i}\right), \\
\Delta S K_{n}=p_{n-1} k_{n-1}+\Delta p\left(K_{0}-\sum_{i=1}^{n-1} k_{i}\right) .
\end{gathered}
$$

The balance of debt growth caused by the loan interest rate growth as a result of the currency rate increase by $\Delta p$ is measured by component $\Delta S K_{n}$ dependent on $\Delta p$ of the estimated principal balance $S K_{n}>0$, , which proves that the principal balance has grown.

The uncertainty of future scenarios of the currency rate growth inclines one to provide an effective instrument for measuring the state of uncertainty, which would enable the continual measurement of the risk of exceeding the acceptable currency rate level. Is this information essential?

An average borrower does not know how to interpret statistical measures of a random vector. The measurement instrument designed here is useful for financial analysts, as they know how to read the estimated risk measures and how to use them creatively in the process of forecasting changes in currency rates, as well as to indicate safeguards against the loan payment consequences.

\section{Conclusion}

The research hypothesis of the study has been positively verified. The domestic currency (PLN) loan indexation has been proved to lead to an unacceptable situation: the debt grows as a result of the currency rate increase, even though principal payments were made. The debt balance change is a random variable, the principal balance being unpredictable in case of the currency rate variations. 
The findings here answer the question about the analysed banking product quality - it does not meet the criteria of a loan. This answer is one aspect of the study. The other one-a positive context - opens an area for further studies on the rolling forecasting methodology applied to risk, with the risk vector componentas taken into consideration.

\section{References}

Aczel A. D., 1993, Complete Business Statistics, Richard D. Irwin, Inc.

Hall R. E., Taylor J. B., 1997, Makroekonomia (Macroeconomics), Państwowe Wydawnictwo Naukowe, Warszawa.

Hubbard D. W., 2010, How to Measure Anything. Finfing the V alue of Intangibles in Business, Published by John Willey \& Sons Inc, Hoboken New Jerseey.

LIBOR frank sqwajcarski 3M w okresie 04.01.2000 do 30.06.2014 (LIBOR swiss franc in period 04.01.2000 to 30.06.2014), www.money.pl (30 may 2015).

Nowak W., 2011, Podstawy metodologii badań w naukach o zarzadzaniu, Wydawnictwo Uniwersytetu Warszawskiego, Warszawa.

Podstawowe stopy procentowe Narodowego Banku Polskiego w latach 1998 -2013 (Basic proportional alloys of National Polish Bank in period 1998-2013), www.nbp.pl (access: 30.05.2015).

Zemke J., 2009, Risk in Handling Financial Liabilities, Measurement Possibilities, Publishing Quality Scientific Research 2009 Littleton USA by The Clute Institute for Academic Research.

Zemke J., 2009, Risks of Organization's Value Chain, "Journal of Business and Economics Research", vol. 7, no. 9, pp. 97-114.

Zemke J., 2009, Ryzyko zarzqdzania organizacja gospodarcza (Risk in economic organization management), Wydawnictwo Uniwersytetu Gdańskiego (Publishing by University Of Gdansk), Gdańsk, Poland.

Zemke J., 2010, How To Measure Changes In The Risk States - Concept Of Definition, "The Journal of Applied Business Research", Vol. 26, No. 5, pp. 87-95.

Zemke J., 2013, Forecasting risk of decision - making processes, Publishing House of Wrocław University of Economics, "ECONOMETRICS”, 1(39), pp. 30-39. 